\title{
Non-invasive measurement of cardiac output by a single breath constant expiratory technique
}

\author{
URI ELKAYAM, ARCHIE F WILSON, JOHN MORRISON, PAUL MELTZER, JAMES \\ DAVIS, PAUL KLOSTERMAN, JED LOUVIER, WALTER L HENRY
}

From the Divisions of Cardiology and Pulmonary Disease, Department of Medicine, University of California, Irvine Medical Center, Orange, California, USA

\begin{abstract}
A new single breath test has been developed that measures pulmonary blood flow $\left(\dot{Q}_{c}\right)$ and pulmonary tissue volume by using the fact that $Q_{c}$ is proportional to the relationship between the absorption rate of acetylene $\left(\mathrm{C}_{2} \mathrm{H}_{2}\right)$ from the alveolar gas and the rate of change of lung volume during constant expiratory flow. To make these measurements a bag in bottle system with a rolling seal spirometer, a mass spectrometer, and a minicomputer with analogue to digital conversion have been used. $\dot{\mathrm{Q}}_{\mathrm{c}}$ was compared with cardiac output measured by the thermodilution technique in 20 patients with cardiac disease; some also had mild chronic obstructive pulmonary disease. The mean (SD) resting $Q_{c}$ for the group was $5.27(1 \cdot 22) 1 / \mathrm{min}$ and the cardiac output measured by thermodilution was $5 \cdot 30(1 \cdot 31) \mathrm{l} / \mathrm{min}$. The mean difference between the two estimations of cardiac output was 0.031 and the standard deviation of this difference was 0.761 . The $\dot{Q}_{c}$ technique was not successful in patients with an $F E V_{1} / F V C$ less that $60 \%$, but seemed to be accurate in those with higher $F E V / F V C$ values. Correction of $\dot{Q}_{c}$ for the effect of venous admixture in 14 patients resulted in an average $19 \%$ overestimation of cardiac output (6.01 $(2.52) \mathrm{l} / \mathrm{min} v 5.05(1.64) \mathrm{l} / \mathrm{min})$. It is concluded that cardiac output can be accurately measured in patients with cardiac or mild pulmonary disease. No correction for venous admixture due to ventilation-perfusion mismatch was necessary in these patients, presumably because the large breath used by the technique overcomes most mild ventilation-perfusion maldistribution. These findings, in addition to the non-invasive nature of the technique, suggest potential value for the measurement of cardiac output in various clinical conditions.
\end{abstract}

Non-invasive tests of cardiopulmonary function based on soluble gas absorption were developed early in this century. ${ }^{1-3}$ Widespread application of these tests, however, has occurred only in the case of the diffusing capacity of the lung for carbon monoxide (TLCO). ${ }^{4}$ The measurement of pulmonary capillary blood flow $\left(\dot{Q}_{c}\right)$ (total cardiac output minus anatomical shunt) has not been widely used, probably because most available techniques are time consuming, cumbersome, or of uncertain reliability. The uncertainty is attributable either to lack of a firm theoretical basis, to lack of clinical validation, or to the unknown effects of breathing manoeuvres and regional maldistribution of function on the measurements. ${ }^{35-8}$

Address for reprint requests: Dr AF Wilson, Department of Medicine, University of California Medical Center, 101 City Drive South, Orange, California 92668, USA.

Accepted 17 October 1983
We have recently introduced a constant expiratory flow single breath technique that is based on analysis of the changes in alveolar gas absorption which occur during individual phases of respiration. This method has a sound theoretical basis ${ }^{8}$ and will be shown below to allow rapid and accurate measurement of cardiac output. In this study we compared pulmonary capillary blood flow measurements obtained by the single breath technique with cardiac output measured simultaneously by a thermodilution technique in patients with cardiovascular and, in some instances, mild pulmonary disorders.

\section{Methods}

\section{THE PATIENTS STUDIED}

The study group (table) was composed of 11 men and 12 women who had undergone diagnostic cardiac catheterisation because of cardiac symptoms. The patients' ages ranged from 20 to 77 years with a 
Data on the 20 patients studied

\begin{tabular}{|c|c|c|c|}
\hline $\begin{array}{l}\text { Age (y) } \\
\text { and sex }\end{array}$ & $\begin{array}{l}\text { Cardiac and/or pulmonary } \\
\text { diagnosis }\end{array}$ & $\begin{array}{l}\text { History of } \\
\text { smoking }\end{array}$ & $\begin{array}{l}\text { Venous admixture } \\
\text { (\% shunt) }\end{array}$ \\
\hline $\begin{array}{ll}65 & \mathrm{~F} \\
30 & \mathrm{~F} \\
40 & \mathrm{~F} \\
47 & \mathrm{~F} \\
20 & \mathrm{M} \\
50 & \mathrm{~F} \\
55 & \mathrm{M} \\
53 & \mathrm{M} \\
63 & \mathrm{M} \\
66 & \mathrm{~F} \\
31 & \mathrm{M} \\
70 & \mathrm{~F} \\
41 & \mathrm{~F} \\
47 & \mathrm{M} \\
52 & \mathrm{M} \\
62 & \mathrm{M} \\
77 & \mathrm{~F} \\
44 & \mathrm{M} \\
44 & \mathrm{~F} \\
42 & \mathrm{M}\end{array}$ & $\begin{array}{l}\text { RHD } \\
\text { IHSS } \\
\text { No cardiac or pulmonary disease } \\
\text { Primary pulmonary hypertension } \\
\text { Non-cardiac pulmonary oedema } \\
\text { RHD and CAD, CABG } \\
\text { CAD, CABG (COPD) } \\
\text { CAD } \\
\text { CAD (COPD) } \\
\text { HTN } \\
\text { RHD } \\
\text { RHD } \\
\text { IHSS } \\
\text { CAD, CABG } \\
\text { CAD, (COPD) } \\
\text { CAD, CABG (COPD) } \\
\text { CAD, CABG } \\
\text { CAD } \\
\text { Coronary spasm } \\
\text { Atrial septal defect }\end{array}$ & $\begin{array}{l}- \\
+ \\
+ \\
+ \\
- \\
- \\
+ \\
\pm \\
+ \\
\text { NA } \\
+ \\
+ \\
+ \\
+ \\
+ \\
- \\
\pm \\
+\end{array}$ & $\begin{array}{l}11 \cdot 1 \\
\text { NA } \\
\text { NA } \\
18 \cdot 0 \\
13 \cdot 0 \\
\text { NA } \\
14 \cdot 2 \\
0 \\
13 \cdot 3 \\
\text { NA } \\
40 \cdot 0 \\
44 \cdot 4 \\
\text { NA } \\
16 \cdot 5 \\
18 \cdot 2 \\
6 \cdot 6 \\
1 \cdot 8 \\
\text { NA } \\
1 \cdot 4 \\
18 \cdot 2\end{array}$ \\
\hline
\end{tabular}

RHD_rheumatic heart disease; IHSS - idiopathic hypertrophic subaortic stenosis; CAD_coronary artery disease; CABG-recovering from coronary artery bypass graft surgery; COPD—chronic obstructive pulmonary disease; HTN-hypertension; NA-not available; + heavy cigarette smoking ( $>20$ cigarettes/day for $>10$ years); \pm light cigarette smoking.

mean of 50 years. Twelve patients had a history of heavy cigarette smoking ( $>20$ cigarettes/day for more than 10 years) and two of a lighter tobacco exposure. Eight patients were non-smokers and in one patient a smoking history was not obtained. Four patients also had chronic obstructive pulmonary disease and one was recovering from noncardiogenic pulmonary oedema. Three patients had more severe chronic obstructive disease $\left(\mathrm{FEV}_{\mathrm{l}} \mathrm{l}\right.$ FVC\% less than $60 \%$-see below); in these patients $\dot{Q}_{c}$ could not be measured reproducibly and their results are not included in the data reported. Of the remaining 20 patients, eight were found to have coronary artery disease, one had coronary spasm, three had valvular heart disease, and one had a combination of coronary and valvular disease. Two patients had idiopathic hypertrophic subaortic stenosis, one had an atrial septal defect, one had primary pulmonary hypertension, and two had no evidence of cardiac disease, although one of them was found to have systemic hypertension. Routine analysis of arterial oxygenation was performed as part of cardiac catheterisation in 14 patients.

\section{SINGLE BREATH CONSTANT EXPIRATORY TECHNIQUE \\ Theory}

During expiratory flow at a constant rate it may be shown $^{8}$ that

$$
\dot{\mathrm{Q}}_{\mathrm{c}}=\frac{\dot{\mathrm{VE}}_{\mathrm{E}}}{\alpha_{\mathrm{t}}} \frac{\ln \mathrm{FA} / \mathrm{FA}_{0}}{\ln \left[\left(\mathrm{VA}+\alpha_{\mathrm{t}} \mathrm{V}_{\mathrm{t}}\right) /\left(\mathrm{VA}_{\mathrm{o}}+\alpha_{\mathrm{t}} \mathrm{V}_{\mathrm{t}}\right)\right]},
$$

where $F A$ is the alveolar concentration of acetylene $\left(\mathrm{C}_{2} \mathrm{H}_{2}\right)$ and $\mathrm{FA}_{0}=\mathrm{FI} / \mathrm{FIHe} / \mathrm{FAHe}$. $\mathrm{FI}$ is inspired acetylene concentration; $\mathrm{FIHe}$ is inspired helium concentration. $\mathrm{VA}$ is alveolar volume and $\mathrm{VA}_{0}$ is $\mathrm{VA}$ at full inspiration and calculated from the formula $V_{A_{0}}=\left(V_{I}-V D\right)(F I H e / F A H e)$, where $V_{I}$ is the inspired volume and $V D$ is dead space. $V E$ is expiratory flow rate, $V_{t}$ is pulmonary parenchymal tissue volume, and $\alpha_{b}$ and $\alpha_{t}$ are Bunsen coefficients for blood and pulmonary tissue. Since FA and VA can be constantly measured during expiratory flow and the other indices are constant, the slope and intercept for $\mathrm{C}_{2} \mathrm{H}_{2}$ during expiration may be calculated on the basis of linear regression. Pulmonary parenchymal tissue volume can be measured directly ${ }^{9}$ but because it has only a small effect on the calculation of $\dot{Q}_{c}{ }^{8}$ it can be estimated $(3.5 \mathrm{~g} / \mathrm{cm}$ height). Since the flow pattern during inspiration may be considered instantaneous and all calculations emanate from expiratory data, there is no need for a constant inspiratory flow rate with this method. Similarly, breath holding time need not be carefully controlled. It is important, however, that expiratory flow should be relatively constant.

\section{Procedure}

Test gas was inspired by the human subjects from a bag in bottle (fig 1). After exhalation to near residual volume, subjects inspired to near total lung capacity through a five way valve connected to the bag, which contained a test gas mixture consisting of $10 \%$ helium, $0.8 \%$ acetylene, $0.1 \%$ carbon 18 labelled carbon monoxide, and $21 \%$ oxygen, with nitrogen making up the balance. The gases were monitored throughout the test with a Perkin-Elmer MGA 1100 mass spectrometer. After a breath hold of about two seconds, the subjects exhaled at a constant rate that varied from 200 to $500 \mathrm{ml} / \mathrm{s}$. At least 


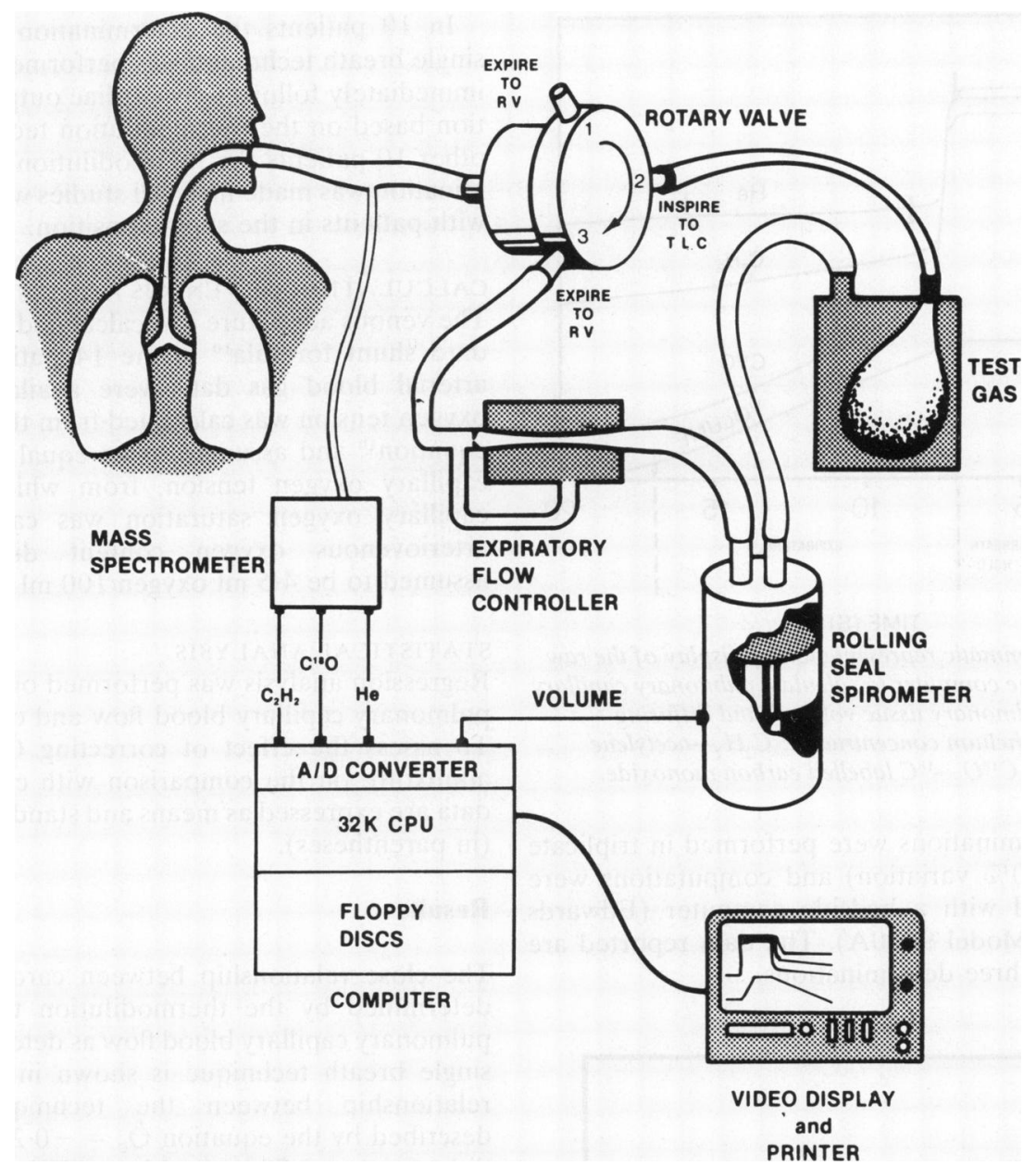

Fig 1 Schematic diagram of equipment used to measure pulmonary capillary blood flow by a single breath technique. $R V \rightarrow$ residual volume; TLC -total lung capacity.

two seconds of expiratory flow were necessary to obtain sufficient data for accurate computation. Correction was made for the presence and effect of water vapour during expiration (assumed to be $47 \mathrm{~mm} \mathrm{Hg}(6.3 \mathrm{kPa}))$. Inspiratory and expiratory volumes as well as expiratory flow rate were monitored by connecting a 12 litre rolling seal spirometer to the bottle and to the expiratory line through a Starling resistor, which was used to maintain a constant expiratory flow. Gas and volume data were monitored on line with a digital computer (Digital Electronics Corporation, PDP 11/23). A typical graphical display of the data on volume and three gas concentrations is shown in figure 2. Alveolar volume (VA) was determined by subtracting the volume expired from the alveolar volume at end inspiration $\left(\mathrm{VA}_{0}\right)$. A linear regression of $\ln \mathrm{FA} / \mathrm{FA}_{0}$ $\left(\mathrm{C}_{2} \mathrm{H}_{2}\right) v \ln \left[\left(\mathrm{VA}+\alpha_{\mathrm{t}} \mathrm{V}_{\mathrm{t}}\right) /\left(\mathrm{VA}_{0}+\alpha_{\mathrm{t}} \mathrm{V}_{\mathrm{t}}\right)\right]$ was com- puted and displayed. A typical graphic display of these calculated data is shown in figure 3. Since data points were usable only after dead space washout and before closing volume, the computer operator selected the limits of the regression data to be used for calculation. From the slope and regression of the data on expired acetylene $Q_{c}$ was calculated. Similarly, TLCO was calculated from the carbon monoxide regression. Reported values are averages of at least two determinations. Usually three or more determinations were made.

\section{CARDIAC OUTPUT DETERMINATION}

A thermodilution Swan-Ganz catheter was inserted in each patient through the femoral vein as a part of cardiac catheterisation. Cardiac output was determined by the thermodilution technique with the use of $5 \%$ dextrose in water as the indicator. Cardiac 


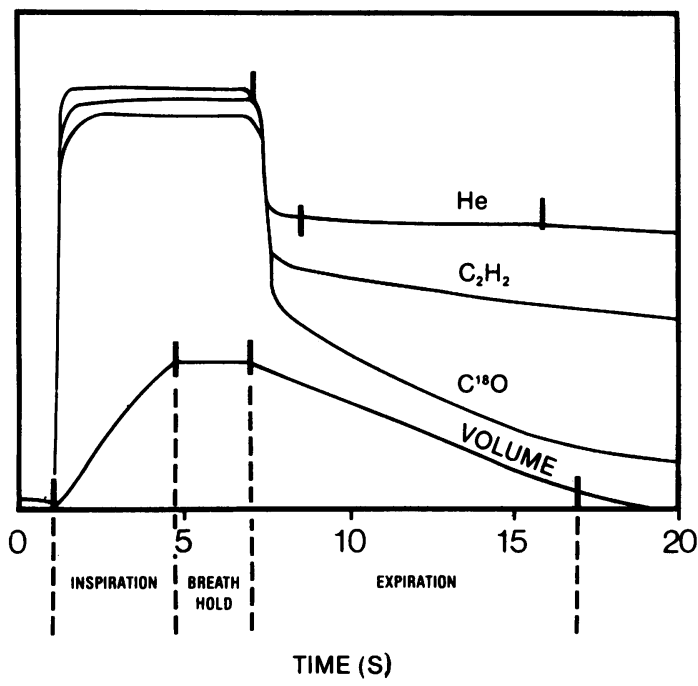

Fig 2 Diagrammatic representation of display of the raw data used by the computer to calculate pulmonary capillary blood flow, pulmonary tissue volume, and diffusing capacity. $\mathrm{He}$-helium concentration; $\mathrm{C}_{2} \mathrm{H}_{2}$-acetylene concentration; $\mathrm{C}^{18} \mathrm{O}-{ }^{18} \mathrm{C}$ labelled carbon monoxide.

output determinations were performed in triplicate (less than $10 \%$ variation) and computations were accomplished with a bedside computer (Edwards Laboratory Model 9520A). The data reported are averages of three determinations.

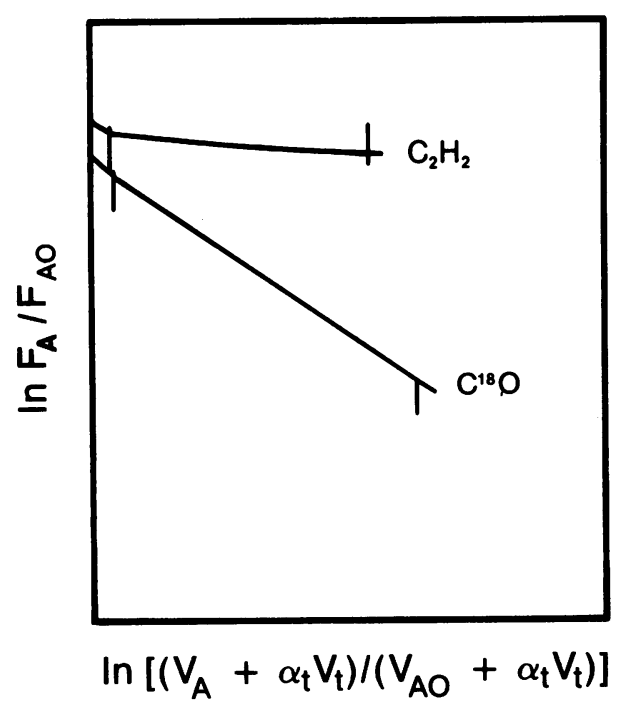

Fig 3 Relationship between acetylene concentration (In $\left.F_{A} / F_{A}\right)$ and alveolar volume plus pulmonary tissue volume $\left(\ln \left[\left(V_{A}+\alpha_{t} V_{t}\right) /\left(V_{A_{0}}+\alpha_{t} V_{t}\right)\right]\right)$ used in the calculation of pulmonary capillary blood flow.
In 10 patients the determination of $\dot{Q}_{c}$ by the single breath technique was performed first and was immediately followed by cardiac output determination based on the thermodilution technique. In the other 10 patients the thermodilution cardiac determination was made first. All studies were performed with patients in the supine position.

\section{CALCULATION OF VENOUS ADMIXTURE}

The venous admixture was calculated from the standard shunt formula ${ }^{10}$ in the 14 patients in whom arterial blood gas data were available. Alveolar oxygen tension was calculated from the alveolar gas equation ${ }^{10}$ and assumed to be equal to pulmonary capillary oxygen tension, from which pulmonary capillary oxygen saturation was calculated. The arteriovenous oxygen content difference was assumed to be $4.5 \mathrm{ml}$ oxygen $/ 100 \mathrm{ml}$ blood.

\section{STATISTICAL ANALYSIS}

Regression analysis was performed on the values of pulmonary capillary blood flow and cardiac output. To assess the effect of correcting $\dot{Q}_{c}$ for venous admixture on the comparison with cardiac output, data are expressed as means and standard deviations (in parentheses).

\section{Results}

The close relationship between cardiac output as determined by the thermodilution technique and pulmonary capillary blood flow as determined by the single breath technique is shown in figure 4 . The relationship between the techniques can be described by the equation $\dot{Q}_{c}=-0.23+1.06$ cardiac output $\pm 0.70 \mathrm{l} / \mathrm{min}$. Mean (SD) cardiac output was $5.30(1.31) \mathrm{l} / \mathrm{min}$ and pulmonary capillary blood flow $5.27(1.22) \mathrm{l} / \mathrm{min}$. The mean difference between techniques was $0.03(0.76) \mathrm{l} / \mathrm{min}$. The $95 \%$ confidence limits for the estimation of the (thermodilution) cardiac output by the single breath method were about \pm 1.49 l.

The mean coefficient of variation for the acetylene measurements was $8.7 \%(4.4 \%)$, which may be contrasted with $7.0 \%(6.4 \%)$ for the thermodilution measurements. The mean value of venous admixture during the breathing of room air was found to be $15.5 \%(13.0 \%)$ in the 14 patients studied. Correction of $\dot{Q}_{c}$ for venous admixture in these 14 patients resulted in considerable overestimation of the data by comparison with the cardiac output (6.01 (2.52) $\mathrm{l} / \mathrm{min} v 5.05 \quad(1.64) ; \mathrm{p}=$ $<0.05)$. No significant difference was found between the uncorrected values of $\dot{Q}_{c}(4.89(1.58) \mathrm{V} /$ min) and the cardiac output as measured by the thermodilution technique $(5.05(1.64) \mathrm{l} / \mathrm{min})$. 


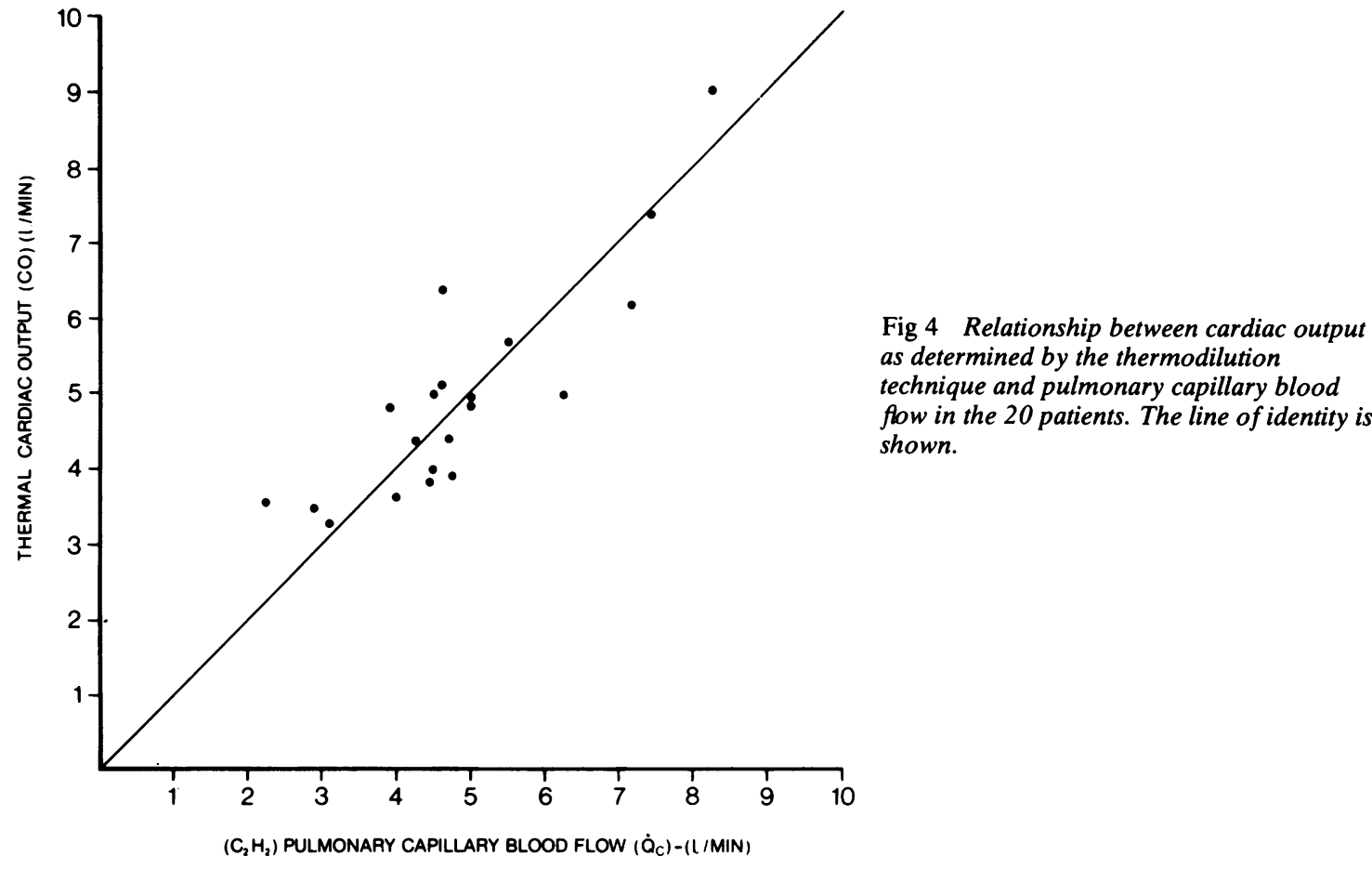

In 12 patients pulmonary function values were available. In three of these patients, the $\ln -\ln$ graphs were not reproducible and were clearly unphysiological. These three patients all had FEV, $/ F V C \%$ values of less than $60 \%$ and were not included in the comparison data of figure 4 . The other patients in whom pulmonary function was evaluated had $\mathrm{FEV}_{\mathrm{l}} / \mathrm{FVC} \%$ values ranging from $66 \%$ to $86 \%$; their data were included in the analysis. Within this small sample of nine there was no correlation between $\mathrm{FEV}_{1} / \mathrm{FVC} \%$ values and thermodilution $/ Q_{c}$ measurement differences.

\section{Discussion}

Assessment of cardiac output is essential to the understanding of cardiocirculatory function and the management of various clinical disorders. The availability of an accurate and convenient noninvasive technique for measuring cardiac output should therefore be of great clinical importance. Most non-invasive methods of measuring cardiac output have considerable inherent limitations and are not in widespread use. For example, $M$ mode echocardiography has been shown to be useful in the assessment of size and function of the left ventricle, especially in normal individuals. ${ }^{112}$ The accuracy of this technique, however, decreases appreciably as the ventricle becomes larger and when segmental wall motion abnormalities develop. ${ }^{13}$ Radionuclide ventriculography has recently been shown capable of producing an accurate assessment of left ventricular volumes and cardiac output. ${ }^{14}{ }^{15}$ The exposure to radioactive material associated with this technique is, however, an important limitation when repeated measurements are needed. Preliminary studies have recently shown that transcutaneous Doppler aortic blood flow measurements made with the aid of echocardiography can provide an accurate assessment of cardiac output. ${ }^{1617}$ Further studies are needed to evaluate this method in disease states.

The use of soluble gas techniques for the determination of pulmonary capillary blood flow and cardiac output is not new. Previous attempts using the solubility characteristics of acetylene, carbon monoxide, and helium have met with varying degrees of success. A multiple single breath technique was first described by Cander and Forster in $1959 .{ }^{3}$ Later a rebreathing method was developed by Sackner et $a l .^{5}$ The multiple single breath method is technically difficult to perform since each breath must have identical inspiratory and expiratory flow rates, and identical beginning and ending lung volumes. An additional possible source of error is that $\dot{Q}_{c}$ may change during the hour or so necessary to complete the measurements. Although Cander and Forster found good agreement between the average esti- 
mated values of cardiac output obtained by their method and the average values of cardiac output measured by the Fick method, as reported by other investigators, no direct comparison was performed. ${ }^{3}$

The rebreathing method described by Sackner et al is more clinically applicable than the multiple single breath technique since it permits rapid measurements ${ }^{5}$ but it involves such rapid, deep breathing that appreciable changes of $\dot{Q}_{c}$ can result during the test. Furthermore, alveolar volumes change rapidly during the test and can be never known with precision, a fact that may introduce an error in calculation of $\dot{Q}_{c}$. Although Sackner et al reported good agreement between $Q_{c}$ as determined by the rebreathing technique and cardiac output as measured simultaneously by the dye dilution method in anaesthetised dogs, ${ }^{5}$ the clinical usefulness of these findings in man has not been assessed.

The single breath constant expiratory technique used in the present study has some other practical advantages over the other two soluble gas techniques. The method is not dependent on reproduction of breath size and beginning lung volume; all the expired gas data are used and the single breath made in performing the test probably does not change the supine $\dot{Q}_{c}{ }^{18}$ Initial clinical evaluation of the technique showed it to be reproducible 9 and the values obtained were close to those expected. The present study shows good agreement between the pulmonary capillary blood flow as measured by this method and cardiac output as determined by the thermodilution technique in patients with cardiac disorders, patients with histories of heavy smoking, and several patients with chronic obstructive lung disease.

Uncertainty about the accuracy of measurements of cardiac output with any soluble gas technique in patients with pulmonary disease is mainly attributable to the unknown effects of appreciable regional maldistribution of ventilation. Data from the three patients with moderately severe lung disease indicate that the technique is not applicable to patients with more than mild obstruction. The technique proved to be accurate, however, in patients with mild chronic obstructive pulmonary disease and some venous admixture. The results suggest that the breathing manoeuvre, which requires inspiration to near total lung capacity, probably overcomes mild to moderate ventilation-perfusion maldistribution. Recalculation of $Q_{c}$ after correction for venous admixture resulted in gross overestimation of the cardiac output as measured by the thermodilution technique. The small difference $(3 \%)$ between measured cardiac output and uncorrected $Q_{c}$ is in good agreement with the known anatomical venous admixture. ${ }^{19}$
Recently Denison and colleagues ${ }^{20}$ have reported the use of a single breath technique based on calculation of $\dot{Q}_{c}$ during expiration over small volume changes. This approach has been contrasted with the other techniques used for the related measurement of diffusing capacity. ${ }^{8}$

Several factors may limit the clinical application of the single breath technique for the assessment of cardiac output. One is the need for expensive equipment such as the mass spectrometer and computer. Another is the need to wait 15-20 minutes between determinations for washout of acetylene. Furthermore, the method is inaccurate in patients with more than mild pulmonary functional alterations.

We have shown that measurement of pulmonary capillary blood flow by a new single breath technique can provide an accurate estimate of cardiac output in patients with cardiovascular or mild chronic obstructive pulmonary disease or both. Correction for the effect of venous admixture using arterial oxygen values is unnecessary. The accuracy, reproducibility, and simplicity of the single breath constant expiratory procedure suggest that it may prove to be a useful technique for the non-invasive determination of cardiac output in normal subjects as well as in patients with cardiac or mild pulmonary disease.

This work was supported in part by a grant from the National Heart, Lung and Blood Institute (PHSHL-1670C-2) and the American Heart Association.

\section{References}

${ }^{1}$ Krogh A, Linhard J. Measurement of blood flow through the lungs of man. Skand Arch Physiol 1912;27:10025.

${ }^{2}$ Bauman H, Grollman A. Über der theoretetischen und praktischen Grundlagen und die klinische Zuverlässigkeit der Acetylenmethode zur Bestimmung des Minutevolumens. Klin Med 1930;115:41-53.

${ }^{3}$ Cander L, Forster RE. Determination of pulmonary parenchymal tissue volume and pulmonary capillary blood flow in man. J Appl Physiol 1959;14:541-50.

${ }^{4}$ Ogilvie CM, Forster RE, Blakemore DS, Morton JW. A standardized breath holding technique for measurement of the diffusing capacity of the lung for carbon monoxide. J Clin Invest 1957;36:1.

${ }^{5}$ Sackner MA, Greeneltch D, Heiman MS, Epstein S, Atkins N. Diffusing capacity, membrane diffusing capacity, capillary blood volume, pulmonary tissue volume and cardiac output measured by a rebreathing technique. Am Rev Respir Dis 1975;111:157-65.

${ }^{6}$ Armitage GH, Arnott WM. Effect of voluntary hyperpnoea on pulmonary blood flow. J Physiol 1949;109:64-9.

${ }^{7}$ Michaelson ED, Sackner MA, Johnson RL jun. Vertical 
distribution of pulmonary diffusing capacity and capillary blood flow in man. J Clin Invest 1973;52:359-69.

${ }^{8}$ Martonen TB, Wilson AF. Theoretical basis of single breath gas absorption tests. J Math Biol 1982;14:203-20.

${ }^{9}$ Morrison JT, Wilson AF, Vaziri MD, Brunsting L, Davis J. Determination of pulmonary tissue volume, pulmonary capillary blood flow and diffusing capacity of the lung before and after hemodialysis. Int J Artif Organs 1980;3:259-62.

:0 Rahn H, Fenn WO. A graphical analysis of the respiratory gas exchange, the $\mathrm{O}_{2}-\mathrm{CO}_{2}$ diagram. Washington DC: American Physiological Society, 1955.

11 Pombo JF, Troy BL, Russell RO jun. Left ventricular volumes and ejection fraction by echocardiography. Circulation 1971;43:480-90.

12 Fortuin NJ, Hood WP jun, Sherman E, Craig E. Determination of left ventricular volumes by ultrasound. Circulation 1971;4:575-84.

${ }^{13}$ Linhart JW, Mintz GS, Segal BL, Kawai N, Kotler MN. Left ventricular volume measurement by echocardiography: fact or fiction? Am J Cardiol 1975;36:114-8.

${ }^{14}$ Slatsky R, Karliner J, Rice D, Kaiser R, Pfisterer M. Left ventricular volumes by gated equilibrium radionuclide angiography: a new method. Circulation 1979;60: $555-64$.
${ }^{15}$ Konstam MA, Wynne J, Holman BL, Brown EJ. Neill JM, Kozlowski RT. Use of equilibrium (gated) radionuclide ventriculography to quantitate left ventricular output in patients with and without left-sided valvular regurgitation. Circulation 1981;64:578-85.

${ }^{16}$ Darsee JR, Walter PF, Nutter DO. Transcutaneous Doppler method of measuring cardiac output. IINon-invasive measurement of transcutaneous Doppler aortic blood velocity integration and $\mathrm{M}$-mode echocardiography. Am J Cardiol 1980;46:613-8.

${ }^{17}$ Gardin JM, Tobis JM, Debestani A, et al. Superiority of two-dimensional measurement of aortic vessel diameter in Doppler echocardiographic estimates of left ventricular stroke volume. Clin Res 1983;31:8A (abstract).

${ }^{18}$ Vermeire P, Butler J. Effect of respiration on pulmonary capillary blood flow in man. Circ Res 1968;22:299308.

${ }^{19}$ Melemgaard K. The alveolar-arterial oxygen difference: its size and components in normal man. Acta Physiol Scand 1966;67:10-20.

${ }^{20}$ Denison DM, Davies NJH, Meyer M, Pierce RJ, Scheid P. Single-exhalation method for study of lobar and segmental lung function by mass spectrometry in man. Respir Physiol 1980;42:87-99. 